\title{
Kosmotropic anion for improving cycling stability of aqueous lithium-ion batteries in salt-in-water electrolytes
}

Hyunjeong Oh

Korea Advanced Institute of Science and Technology

\section{Seung-Jae Shin}

Korea Advanced Institute of Science and Technology

Hirona Yamagishi

Ritsumeikan University

\section{Toshiaki Ohta}

Ritsumeikan University

\section{Naoaki Yabuuchi}

Yokohama National University https://orcid.org/0000-0002-9404-5693

\section{Hyungjun Kim}

Korea Advanced Institute of Science and Technology https://orcid.org/0000-0001-8261-9381

Hye Ryung Byon ( $\nabla$ hrbyon@kaist.ac.kr)

Korea Advanced Institute of Science and Technology https://orcid.org/0000-0003-3692-6713

\section{Article}

Keywords: aqueous lithium-ion batteries, kosmotropic anions, LiCoO2 electrode

Posted Date: May 19th, 2021

DOl: https://doi.org/10.21203/rs.3.rs-525052/v1

License: (c) (1) This work is licensed under a Creative Commons Attribution 4.0 International License. Read Full License 


\section{Abstract}

The incompatibility between $\mathrm{Li}^{+}$-intercalated electrodes and water limits the practical feasibility of aqueous lithium-ion batteries (LIBs), which are economical and environmentally benign energy storage systems. Tremendous amounts of salts dissolved in water (water-in-salt) have been utilized to mitigate the access of water to the electrode/electrolyte interface and to extend the electrochemical potential window of aqueous LIBs. However, this approach has low viability owing to the expense of the salts. Here, we show that kosmotropic anions with moderate concentrations $\left(0.5 \sim 3 \mathrm{~mol} \mathrm{~kg}^{-1}\right)$ protect the $\mathrm{LiCoO}_{2}$ electrode by harnessing water molecules. The sulfates of kosmotropic anions develop rigid watersolvation shells and also form ion pairs with $\mathrm{Li}^{+}$. All-atomic-level multiscale simulation revealed that sulfates tied with $\mathrm{Li}^{+}$and the water shell are highly concentrated at the interface, thus decreasing the density of free water. The suppressed water activity explains the superior cell performance achieved with $0.5 \mathrm{~mol} \mathrm{~kg}^{-1}$ sulfate relative to that in cells with $1 \mathrm{~mol} \mathrm{~kg}^{-1}$ of chaotropic anions such as nitrate, perchlorate, and bis(trifluoromethylsulfonyl)imide. The formation of a liquid-phase protective layer is a new concept for developing stable aqueous batteries without the requirement for a solid-state electrolyte or an artificial protective layer on the electrode.

\section{Introduction}

With the increasing importance of safety, cost, and eco-friendliness, rechargeable batteries employing aqueous medium have received much attention as suitable for grid-scale energy storage systems (ESSs) ${ }^{1-3}$ Aqueous lithium-ion batteries (LIBs) are one of the most feasible systems for industrialization as they can be promptly developed by transformation of well-established non-aqueous LIBs. However, most $\mathrm{Li}^{+}$-intercalating electrodes are incompatible with water, undergoing swift structural deformation, which results in poor cell performance. ${ }^{4-7}$ Recently, invaluable studies on water-in-salt electrolytes (WiSEs) have been demonstrated using very large amounts of bulky imide anions, such as $21 \mathrm{~m}$ (molal concentration, mol kg${ }^{-1}$ ) bis(trifluoromethylsulfonyl)imide ( $\mathrm{TFSI}^{-}$) and additional bis(pentafluoroethylsulfonyl)imide. ${ }^{8,9,10}$ The limited free-water concentration and the formation of aggregated ion pairs in WiSEs alter the cell chemistry to establish a dense protective surface layer and widen the potential window. ${ }^{8,11-13}$ Nevertheless, utilizing WiSEs in practical aqueous LIBs is inexpedient because of the high cost of the large amount of salts and easy crystallization of the symmetrically structured anions. ${ }^{10,14,15}$

Therefore, a more desirable approach is to maintain salt-in-water electrolytes and control the content of water and protons $\left(\mathrm{H}^{+}\right)$, which are much more abundant than the electrolyte salts, to stabilize the $\mathrm{Li}^{+}-$ intercalating electrodes. Water deforms the electrode surface chemically during cell operation. ${ }^{4,16}$ Furthermore, the dissociation of water produces $\mathrm{H}^{+}$, which is irreversibly inserted into the electrode structures and expedites capacity fading over a wide $\mathrm{pH}$ range. ${ }^{17-21}$ To curtail structural deformation of the electrodes, inorganic and graphitic protective layers have been introduced onto the electrode 
surface. ${ }^{22-24}$ However, these solid-state layers may retard ion transport at the interface and generate cracks during cycling.

Instead, we herein introduce the new concept of a liquid-state protective layer formed with moderate concentrations $(0.5 \sim 3 \mathrm{~m})$ of anions. The key principle is to enhance the interaction of the anion with both water and $\mathrm{Li}^{+}$, and reduce the activity of free water molecules that are considered to be the source of $\mathrm{H}^{+}$. It is found that sulfate $\left(\mathrm{SO}_{4}{ }^{2-}\right)$, as a kosmotropic anion, mitigates the detrimental deformation of the lithium cobalt oxide $\left(\mathrm{LiCoO}_{2}\right.$, denoted as $\left.\mathrm{LCO}\right)$ electrode. The rigid water structure formed adjacent to the kosmotropic anion aids in improving the cell cyclability. The structural details of the electrode-electrolyte interface are investigated using multiscale $\mathrm{QM} / \mathrm{MM}$ simulations, revealing that the high charge density of the kosmotropic anion in the interfacial region induces localized concentration of the $\mathrm{Li}^{+}$ions and lowers the free water density. In stark contrast, diffuse chaotropic anions such as $\mathrm{TFSI}^{-}$, nitrate $\left(\mathrm{NO}_{3}{ }^{-}\right)$, and perchlorate $\left(\mathrm{ClO}_{4}{ }^{-}\right)$neither strongly controlled the water shell nor formed ion pairs. The resulting capacity fading with the chaotropic anions is in stark contrast with that of the kosmotropic system.

\section{Results And Discussion}

The galvanostatic cyclability of the LCO electrodes was first evaluated using two representative electrolyte salts, namely, $0.5 \mathrm{~m} \mathrm{Li}_{2} \mathrm{SO}_{4}$ and $1 \mathrm{~m} \mathrm{LiTFSI}$, which both provided $1 \mathrm{~m} \mathrm{Li}^{+}$. The LCO electrode with $0.5 \mathrm{~m} \mathrm{Li}_{2} \mathrm{SO}_{4}$ exhibited a gradual increase in capacity at $0.5 \mathrm{C}$ over 30 cycles as the wetting of the electrode increased, ${ }^{5}$ and the coulombic efficiency (CE) approached $97 \%$ (Figure 1a and 1c). By comparison, $1 \mathrm{~m}$ LiTFSI reduced the capacity from 110 to $30 \mathrm{mAh} \mathrm{g}^{-1}$ (Figure 1b) and afforded an inferior CE of $94 \%$ (Figure 1c). Rate-capability tests with $1 \mathrm{~m} \mathrm{LiTFSI} \mathrm{displayed} \mathrm{an} \mathrm{ill-defined} \mathrm{capacity} \mathrm{at}$ various current rates (Figure 1d). In contrast, complete recovery of the capacity was found for the LCO electrode with $0.5 \mathrm{~m} \mathrm{Li}_{2} \mathrm{SO}_{4}$ at the terminating $0.2 \mathrm{C}$ after $10 \mathrm{C}$ operation. These results reveal that the cyclability and rate capability of the LCO electrode are both anion-dependent.

To determine the origin of the capacity fading, the short-range order of the LCO structure was analyzed using soft X-ray absorption fine structure (XAFS) spectroscopy. ${ }^{7}$ In surface-sensitive partial electron yield (PEY) mode ( $<10 \mathrm{~nm}$ depth), the $\mathrm{Co}^{3+} 3 d-02 p$ hybridization peak in the oxygen (0) $K$ edge spectra (529.8 $\mathrm{eV}$ ) was attenuated for both LCO electrodes after 30 cycles. In addition, a new signal emerged at $531.4 \mathrm{eV}$, attributed to partial oxidation of the lattice oxide of LCO; this signal is denoted as 01 (Figure 1e-f). ${ }^{25-27}$ The 01 signal was particularly intense for LCO with $1 \mathrm{~m} \mathrm{LiTFSI,} \mathrm{indicating} \mathrm{more} \mathrm{extensive} \mathrm{surface}$ oxidation than in the case with $0.5 \mathrm{~m} \mathrm{Li}_{2} \mathrm{SO}_{4}$. In bulk-sensitive partial fluorescence yield (PFY) mode (> $100 \mathrm{~nm}$ depth), the $\mathrm{Co}^{4+} 3 d\left(\mathrm{t}_{2 \mathrm{~g}}{ }^{5} \mathrm{e}_{\mathrm{g}}{ }^{0}\right)-02 p$ hybridization band was observed at $528 \mathrm{eV} ;{ }^{25-27}$ this band is denoted as $\mathbf{0 2}$ (Figure 1f). The signal was more pronounced with $1 \mathrm{~m} \mathrm{LiTFSI}$, consistent with a subtle shift of the main $\mathrm{Co}^{3+}$ signals to higher energy than others in the Co $L_{2}$ and $L_{3}$ edge spectra (Figure S1). Because the $\mathbf{O} 2$ signal should disappear after $\mathrm{Li}^{+}$intercalation during the discharging process, its existence after 30 cycles indicates incomplete $\mathrm{Li}^{+}$intercalation into the LCO electrode. The remaining $\mathrm{Li}$ 
vacancy and $\mathrm{Co}^{4+}$ cause local distortion of the octahedral $\mathrm{CoO}_{6}$ unit. ${ }^{7,27}$ Long-range structural transformation was also observed. Powder X-ray diffraction analysis of the LCO electrode after operation with $1 \mathrm{~m}$ LiTFSI displayed split peaks related to the 003 reflection (Figure S2). The new peak appearing at $18.7^{\circ}$ indicates widening of the interlayer distance due to the deficiency of $\mathrm{Li}^{+} .4,28$ In contrast, a less profound 02 signal was observed with $0.5 \mathrm{~m} \mathrm{Li}_{2} \mathrm{SO}_{4}$ in the XAFS profile, along with a single 003 reflection, indicating complete $\mathrm{Li}^{+}$intercalation into $\mathrm{LCO}$ after the same number of cycles.

Such inadequate $\mathrm{Li}^{+}$intercalation has been ascribed to the insertion of $\mathrm{H}^{+}$into the $\mathrm{LCO}$ electrode in previous studies. ${ }^{17-20} \mathrm{H}^{+}$can be produced through the dissociation of water at the electrode surface in neutral or weakly alkaline solutions. Electrochemical impedance spectroscopy (EIS) can be used to distinguish $\mathrm{Li}^{+}$intercalation and $\mathrm{H}^{+}$insertion in the LCO electrode. ${ }^{19}$ Successive Nyquist plots were acquired at open-circuit potential (OCP, Figure S3), during the charging process (from $0.66 \mathrm{~V}$ to $0.8 \mathrm{~V}$, red to yellow curves), and the discharging process (from $0.8 \mathrm{~V}$ to $0.63 \mathrm{~V}$, light green to dark green curves) for three galvanostatic cycles (Figure 2). The emerging semicircle at the beginning of the $1^{\text {st }}$ charge is attributed to the charge-transfer resistance of $\mathrm{Li}^{+}\left(R_{c t, L i+}\right){ }^{19,20,29}$ The increased electronic conductivity of LCO decreased the semicircle size during the charging process, as a result of transformation from the semiconductor to the semi-metal by $\mathrm{Li}^{+}$extraction. ${ }^{30}$ During the discharging process, the semicircle gradually increased again with $0.5 \mathrm{~m} \mathrm{Li}_{2} \mathrm{SO}_{4}$. Enlargement of the semicircle at the end of discharge $(0.63$ V) reflects $\mathrm{Li}^{+}$filling at the topmost surface of the LCO electrode (Figure 2a-b). ${ }^{31}$ This behavior was repeated for all three cycles, and $R_{c t, L i+}$ was estimated as $27.8 \Omega$ after 30 cycles (Figure S4a and Table S1). In comparison, the Nyquist plot of the LCO electrode with $1 \mathrm{~m} \mathrm{LiTFSI} \mathrm{showed} \mathrm{a} \mathrm{larger} \mathrm{semicircle}$ corresponding to $R_{C t, L i+}$ at the beginning of the $1^{\text {st }}$ charge (Figure $2 \mathbf{c}-\mathbf{d}$ ). More importantly, a new semicircle was observed in the low-frequency region at the terminal stage of the discharge process. Although this new semicircle vanished at the beginning of the following charging process over three cycles, it eventually grew irreversibly and accounted for a larger portion of the resistance $(\sim 147 \Omega)$ after 30 cycles (Figure S4b and Table S1). This semicircle, which is apparently distinguished from that associated with $R_{C t, L i+}$ is attributed to the resistance from $\mathrm{H}^{+}$insertion $\left(R_{C t, \mathrm{H}_{+}}\right) .{ }^{19,20}$ The result of $\mathrm{H}^{+}$ insertion appeared at the end of the discharging process, that is, at the terminal stage of $\mathrm{Li}^{+}$intercalation. This behavior was not observed with $0.5 \mathrm{~m} \mathrm{Li}_{2} \mathrm{SO}_{4}$.

The intriguing question is which factor related to the electrolyte salt leads to the distinct degree of $\mathrm{H}^{+}$ insertion. Three possible factors were postulated: the $\mathrm{pH}$, surface protective layer, and anion effects. The $1 \mathrm{~m} \mathrm{LiTFSI}$ solution had a pH of 8, which is lower than that (pH 9.6) of the $0.5 \mathrm{~m} \mathrm{Li}_{2} \mathrm{SO}_{4}$ solution (Figure S5). When the $\mathrm{pH}$ of the LiTFSI solution was adjusted to $\sim 10$ by adding $\mathrm{LiOH}$, the capacity retention of LCO was still limited to $34 \%$, which is far inferior to the value of $\sim 100 \%$ achieved with $0.5 \mathrm{~m} \mathrm{Li}_{2} \mathrm{SO}_{4}$. The Nyquist plot for the LCO electrode with $1 \mathrm{~m} \mathrm{TFSI}^{-}(\mathrm{pH} \mathrm{10})$ revealed suppression of $\mathrm{H}^{+}$insertion in the $1^{\text {st }}$ cycle (Figure S6). Nonetheless, the $R_{C t, H_{+}}$signal appeared at the end of the $3^{\text {rd }}$ cycle (Figure S6), and both semicircles designated to $R_{C t, L i+}$ and $R_{c t, H+}$ grew over the course of 10 cycles (Figure S7), which is in line 
with the capacity fading. ${ }^{32}$ In stark contrast, the $R_{c t, H_{+}}$signal did not appear for $\mathrm{LCO}$ with $0.5 \mathrm{~m} \mathrm{Li}_{2} \mathrm{SO}_{4}$ at the $10^{\text {th }}$ cycle, elucidating negligible capacity decay. Therefore, the $\mathrm{pH}$ effect was not critical under mildly alkaline conditions.

The formation of a solid-state protective layer on the LCO electrode was then considered. In non-aqueous media, decomposition of the electrolyte solution is accompanied by the construction of an interphase layer that serves to mitigate undesired surface reactions. ${ }^{33,34}$ However, both $\mathrm{SO}_{4}{ }^{2-}$ and $\mathrm{TFSI}^{-}$are inert in the given potential range. The X-ray photoelectron spectra (XPS) did not reveal any $\mathrm{SO}_{4}{ }^{2-}, \mathrm{TFSI}^{-}$, or fragmental species of the electrolytes after 30 cycles (Figure S8). In the 01 s binding energy region, the signal of lattice $\mathrm{Co}-\mathrm{O}$ at $529.7 \mathrm{eV}$ was less intense, while the peak at $530.8 \mathrm{eV}$ indicating both the oxide defects $\left(0^{-2+\delta}\right)$ and the hydroxide became significant. This surface deformation was inevitably and chemically induced by the contact of the electrode with water, especially after $\mathrm{Li}^{+}$extraction (Figure S9). ${ }^{4,6,16}$ Therefore, the above results indicate the absence of a solid-state protective layer over the LCO electrode. After 30 cycles, a thicker amorphous surface layer was formed on the LCO with $1 \mathrm{~m} \mathrm{LiTFSI}$, as observed in the transmission electron microscope images (Figure S10), demonstrating more acute surface degradation than that with $0.5 \mathrm{~m} \mathrm{Li}_{2} \mathrm{SO}_{4}$.

Therefore, we focused on the last factor, the effect of the anion type. $\mathrm{SO}_{4}{ }^{2-}$ and TFSI ${ }^{-}$are well-known as strong kosmotropic and chaotropic ions, respectively, according to the Hofmeister series. ${ }^{35-38}$

Kosmotropic anions undergo intimate interactions with water and form a rigid solvation structure. ${ }^{39,40}$, In contrast, chaotropic anions, such as $\mathrm{NO}_{3}{ }^{-}, \mathrm{ClO}_{4}{ }^{-}$, and $\mathrm{TFSI}^{-}$, undergo weak interactions with water that induce disorder of the surrounding water structure. By investigating $\mathrm{NO}_{3}{ }^{-}$and $\mathrm{ClO}_{4}{ }^{-}$having less chaotropic character than $\mathrm{TFSI}^{-}$, the effect of the anions on the cell cyclability was elucidated (Figure $3 a-b)$, where the molal concentration of all electrolyte salts was similar to the molar concentration $(M$, mol L ${ }^{-1}$, Table S2). The LCO electrode with $0.5 \mathrm{~m} \mathrm{Li}_{2} \mathrm{SO}_{4}$ showed $\sim 73 \%$ capacity retention after 100 cycles. In comparison, $1 \mathrm{~m} \mathrm{LiNO}_{3}$ and $1 \mathrm{~m} \mathrm{LiClO}_{4}$ exhibited lower retentions of $33 \%$ and $13 \%$, respectively. With the use of $1 \mathrm{~m} \mathrm{LiTFSI}$, the capacity decreased immediately after 30 cycles, and the CE of $94 \%$ was lower than that $(>99 \%)$ achieved with all other electrolytes. Consequently, the cell performance was very distinct and followed the order: $\mathrm{SO}_{4}{ }^{2-}>\mathrm{NO}_{3}{ }^{-}>\mathrm{ClO}_{4}{ }^{-}>\mathrm{TFSI}^{-}$, which corresponds to the reinforcing kosmotropic nature of the anion. Consistently, it appears to larger $R_{C t, L i+}$ of $\mathrm{LCO}$ with $\mathrm{NO}_{3}{ }^{-}$than that with $\mathrm{SO}_{4}{ }^{2-}$ (Figure S11a). The presence of $\mathrm{ClO}_{4}{ }^{-}$promotes the formation of $R_{c t, H+}$ (Figure S11b). All these evidences support the decisive correlation between the surface reaction and cyclability.

The anion interaction perturbs the $\mathrm{O}-\mathrm{H}$ vibrations of the water molecules, which are sensitive to the strength of the hydrogen bond. Infrared (IR) spectroscopy allows distinction of the vibrational bands of the $\mathrm{O}-\mathrm{H}$ stretching at $\sim 3200 \mathrm{~cm}^{-1}$ for the strongest and ordered water structure versus that at $\sim 3400$ $\mathrm{cm}^{-1}$ for the weaker hydrogen bond. ${ }^{41}$ When $\mathrm{Li}_{2} \mathrm{SO}_{4}$ was added to the water in concentrations from 0.1 to $3 \mathrm{~m}$, the $\mathrm{O}-\mathrm{H}$ band at $\sim 3200 \mathrm{~cm}^{-1}$ gradually intensified as the hydrogen-bond became stronger (Figure 
3c). This result may be attributed to the $\mathrm{Li}^{+}$-water interaction, because the hydrogen bond of the water network is negligibly perturbed by $\mathrm{SO}_{4}{ }^{2-}{ }^{-42}$ In other words, the $\mathrm{SO}_{4}{ }^{2-}$-water interaction is as strong as the water network, thus providing a featureless signal. In sharp contrast, the IR band of $\mathrm{LiNO}_{3}$, $\mathrm{LiClO}_{4}$, and LiTFSI at $3200 \mathrm{~cm}^{-1}$ became less intense in the order: $\mathrm{NO}_{3}{ }^{-}<\mathrm{ClO}_{4}{ }^{-}<\mathrm{TFSI}^{-} .41,43-45$ This trend underpins the disordering of the solvation structure with increasing chaotropic nature of the anion. Additionally, the signals at $3500 \sim 3650 \mathrm{~cm}^{-1}$ are related to both the free water and the chaotropic anionwater interaction. ${ }^{42,46-48}$ More pronounced absorption bands appeared at higher electrolyte concentrations, supporting the latter phenomenon. Figure $\mathbf{S 1 2}$ shows different $\mathrm{O}-\mathrm{H}$ vibrations depending on the anion type in the presence of $1 \mathrm{~m} \mathrm{Li}^{+}$. Note that the range of influence of ions on the structure of water has been debated, from the first solvation shell to the mid/long-range hydrogen-bonding network. ${ }^{39,40,49}$ Nonetheless, it is generally agreed that the anions have profound impact on the closest water molecules, and the strength of their interactions in the first solvation shell can determine the macroscopic properties of the electrolyte solution. ${ }^{40}$

More important is the effect of the anions on water structuring at the electrode surface, in accounting for the electrode deformation and the corresponding cell performance. The water structure in the bulk solution can be altered at the interfacial region by the local concentration of ions, surface charge of the electrode, material property, and applied electric field. ${ }^{50,51}$ The staircase-potential EIS in the non-faradaic potential region was quantified to electric double layer $(E D L)$ capacitance $\left(C_{\mathrm{dl}}\right)$ on the LCO electrode (Figure 4a and Figure S13). In addition, the surface charge density $(s)$ was calculated using Eq. 1 (Figure 4b):

$$
\sigma=\int_{U^{\mathrm{PzC}}}^{U} C_{\mathrm{dl}}\left(U^{\prime}\right) d U^{\prime}
$$

where $U$ is the electrode potential, and $U^{P Z C}$ is the potential at the point of zero charge (PZC) where $C_{\mathrm{dl}}$ approaches the minimum value. Figure 4a shows that the $C_{\mathrm{dl}}$ of $1 \mathrm{~m}$ LiTFSI is $1.5 \sim 3$ times higher than the $C_{\mathrm{dl}}$ of the other electrolytes in the given potential range of $0.3 \sim-0.3 \mathrm{~V} \mathrm{vs}$. $\mathrm{Ag} / \mathrm{AgCl}$. It is attributed to large van der Waals volume, high polarizability, and mild hydrophilicity of $\mathrm{TFSI}^{-52-54}$ affording the excellent adsorption for both LCO material and carbon additive part in the EDL region (Figure S14). However, a higher $C_{\mathrm{dl}}$ does not necessarily mean a higher concentration of ion present at the "interface", due to the possible formation of ion pairs. As the ion pairs do not contribute to the $C_{\mathrm{dl}}$ associated with the net surface charge, it is suggested to the necessity of full elucidation on the interfacial structure.

The detailed atomic arrangement of the interfacial structure formed th the LCO electrode was explicated using our recently developed mean-field QM/MM simulation. ${ }^{55}$ To investigate the electrolyte response to the cathodic charging, two different surface charge densities of $s=0$ and $-11.5 \mathrm{mC} \mathrm{cm}^{-2}$ were compared. First, the local ion concentration along the surface normal direction (which was chosen as the 
z-direction) revealed the formation of two layers within ca. $6 \AA$ from the topmost atoms of the LCO electrode (Figure S15a-b). Additionally, the local water concentration also showed a layering tendency near the electrode surface, and then converged into the bulk value at $z>6 \AA$ (Figure S15c). Thus, it is reasonably assumed that the region at $z<6 \AA$ is an interfacial region, that is, a part of the EDL (nanometer scale) in direct contact with the solid electrode, at which the ion concentration and free water density were analyzed.

Figure $4 \mathrm{c}$ shows the number of anions located in the interfacial region when the aqueous electrolyte was interfaced with the LCO electrode. Notably, the local anion population near the electrode increased at $s=$ $0 \mathrm{mC} \mathrm{cm}{ }^{-2}$ as the ion became more kosmotropic; $\mathrm{SO}_{4}{ }^{2-}$ showed the largest population. A water adlayer was formed on the LCO surface (Figure S16), which can attract ions to the interfacial region via ion-dipole interactions. Because the ion-dipole interaction can be maximized for ions with a high charge density, kosmotropic ions such as $\mathrm{SO}_{4}{ }^{2-}$ can accumulate in large quantities near the electrode surface.

Surprisingly, such a trend still holds even when the LCO electrode is cathodically polarized $(s=-11.5 \mathrm{mC}$ $\mathrm{cm}^{-2}$ ), where the anions experience electrostatic repulsion from the electrode (compare triangles and squares in Figure 4c). The LCO surface attracts $\mathrm{Li}^{+}$, which is further stabilized by the water adlayer (Figure 4d). In parallel, $\mathrm{Li}^{+}$electrostatically attracts anions to form ion pairs. Kosmotropic anions having high charge density are now preferentially associated with small-size $\mathrm{Li}^{+}$ions (Figure 4e), according to the "hard and soft acid and base (HSAB)" concept. The present simulation shows that contact ion pairs (CIPs) are more favorably formed when the anions have more kosmotropic character (Figure S17).

Along with the large increase in the local ion concentration (including $\mathrm{Li}^{+}$) with kosmotropic anions, the increased ionic strength near the electrode surface can minimize the number of uncoordinated water molecules, termed 'free water'. This demonstrates the inverse relationship between the density of free water and the kosmotropic propensity of the anions (Figure 4f). Considering that the electrolyte $\mathrm{pH}$ is in the mildly alkaline range where water is regarded as the main $\mathrm{H}^{+}$source, the lower free water density induced by the kosmotropic anions conceivably helps to suppress $\mathrm{H}^{+}$insertion and maintain the stability of the electrode.

When the potential rose above $0.2 \mathrm{~V}$, that is, positive $s$, the $C_{\mathrm{dl}}$ increased substantially for all electrolytes (Figure 4a) because many anions approach the EDL through electrostatic interactions. At $0.3 \mathrm{~V}$, the $s$ values for $\mathrm{Li}_{2} \mathrm{SO}_{4}$ and $\mathrm{LiTFSI}$ became comparable and were slightly higher than those of $\mathrm{LiNO}_{3}$ and $\mathrm{LiClO}_{4}$ (Figure 4b). The increased anion concentration can enhance the stability of the electrode against water, regardless of the anion type. It is demonstrated by the shift of the cutoff potential from $-0.2 \mathrm{~V}$ to $0.3 \mathrm{~V}$; the capacity retention was significantly increased from $<35 \%$ to $56 \%$ with $1 \mathrm{~m} \mathrm{LiNO}_{3}, 65 \%$ with $1 \mathrm{~m}$ $\mathrm{LiClO}_{4}$, and 21\% with $1 \mathrm{~m} \mathrm{LiTFSI} \mathrm{over} 200$ cycles (Figures S18-19 and Table S3). The cell with $0.5 \mathrm{~m}$ $\mathrm{Li}_{2} \mathrm{SO}_{4}$ still exhibited superior performance $(67 \%)$ despite utilizing approximately half the concentration of the other anions. From the increasing $C_{\mathrm{dl}}$ at positive potential, we anticipate that the concentration of anions at the electrode surface would be similar for all electrolytes in the Faradaic potential region where 
the $\mathrm{Li}^{+}$intercalation/extraction process occurs $\left(0.5 \sim 0.8 \mathrm{~V} \mathrm{vs}\right.$. Ag/AgCl). If $\mathrm{Li}^{+}$intercalation competes with $\mathrm{H}^{+}$insertion, a high $\mathrm{Li}^{+}$concentration near the LCO electrode is beneficial. Therefore, the ion pair formed by $\mathrm{SO}_{4}{ }^{2-}$ is more likely to reduce the detrimental effect of water.

Based on the insights gained from the above studies, we attempted to improve the cell performance by increasing the concentration of $\mathrm{SO}_{4}{ }^{2-}$. The electrochemical potential window in the anodic region was slightly expanded with $3 \mathrm{~m} \mathrm{Li}_{2} \mathrm{SO}_{4}(\sim 130 \mathrm{mV}$, Figure $5 \mathrm{a})$, implying that more $\mathrm{SO}_{4}{ }^{2-}$ was localized on the electrode and suppressed the water reaction. ${ }^{8,56}$ The $\mathrm{O}-\mathrm{H}$ vibration of $3 \mathrm{~m} \mathrm{Li}_{2} \mathrm{SO}_{4}$ was analogous to that with $0.5 \mathrm{~m} \mathrm{Li}_{2} \mathrm{SO}_{4}$ in the Raman and ATR-IR spectra (Figure $3 \mathrm{c}$ and Figure S20), while the symmetric $\mathrm{SO}_{4}{ }^{2-}$ stretching mode in the Raman spectrum was blue-shifted at higher concentrations due to the significant formation of ion pairs (Figure 5b) ${ }^{57,58}$ Consistently, the appearance of an IR-inactive stretching band and the red-shift of the anti-symmetric $\mathrm{SO}_{4}{ }^{2-}$ vibration evidenced the growing number of ion associations (Figure S21). ${ }^{44}$

Full-cells composed of $\mathrm{Li}_{9 / 7-x} \mathrm{Nb}_{2 / 7} \mathrm{Mo}_{3 / 7} \mathrm{O}_{2}$ (LNMO) as the negative electrode, $\mathrm{LCO}$ as the positive electrode, ${ }^{59,60}$ and aqueous electrolyte solutions with different salt concentrations $\left(0.5,3 \mathrm{~m} \mathrm{Li}_{2} \mathrm{SO}_{4}, 1\right.$ and $3 \mathrm{~m} \mathrm{LiTFSI}$, and $9 \mathrm{~m} \mathrm{LiNO}_{3}$ ) were assembled. With the low-concentration electrolyte, LNMO limited the cell capacity to $40 \sim 90 \mathrm{mAh} \mathrm{g}^{-1}$ LCO (Figure S22). The $0.5 \mathrm{~m} \mathrm{Li}_{2} \mathrm{SO}_{4}$ and $1 \mathrm{~m} \mathrm{LiTFSI-based} \mathrm{full-cells} \mathrm{both}$ experienced rapid capacity fading over 50 cycles (Figure $5 \mathrm{c}$ ) owing to the deformation of LNMO and the hydrogen evolution reaction in the salt-in-water system. In comparison, $3 \mathrm{~m} \mathrm{Li}_{2} \mathrm{SO}_{4}$ delivered $74 \%$ capacity retention over 500 cycles, which is superior to that achieved with $3 \mathrm{~m} \mathrm{LiTFSI} \mathrm{(38 \% )} \mathrm{and} 9 \mathrm{~m}$ $\mathrm{LiNO}_{3}$ (34\%) (Figures $\mathbf{5 c}-\mathbf{d}$, Figure S23, and Table S4). The outstanding cyclability attained using $3 \mathrm{~m}$ $\mathrm{Li}_{2} \mathrm{SO}_{4}$ is attributed to the extensive $\mathrm{SO}_{4}{ }^{2-}$-based liquid protective layer that harnesses the water molecules. Although the cells with $1 \sim 3 \mathrm{~m} \mathrm{LiTFSI} \mathrm{exhibited} \mathrm{higher} \mathrm{initial} \mathrm{capacity} \mathrm{than} \mathrm{those} \mathrm{with} \mathrm{the}$ corresponding $\mathrm{Li}_{2} \mathrm{SO}_{4}$, prompt capacity fading was observed during cycling. In addition, the poor cyclability of $9 \mathrm{~m} \mathrm{LiNO}_{3}$ confirmed the indispensable role of the kosmotropic anions. Although the cell stability with the salt-in-water electrolyte is still inferior to that of WiSE (92\% capacity retention with $21 \mathrm{~m}$ LiTFSI, Figure S24), this finding provides promise for developing aqueous LIBs with far lower electrolyte concentrations by tailoring the anion species.

In summary, we demonstrated the imperative role of anions in the salt-in-water electrolyte of aqueous LIBs. In the presence of chaotropic anions, severe capacity fading appeared due to deformation of the LCO surface by water and $\mathrm{H}^{+}$insertion. In contrast, sulfate, as a kosmotrope, mitigated these detrimental effects by establishing stronger sulfate-water and sulfate- $\mathrm{Li}^{+}$ion interactions. Atomic-scale multiscale simulations illuminated the higher local concentration of sulfate at the interfacial region of the LCO electrode. The stiff water structures and kosmotropic anion- $\mathrm{Li}^{+}$pairs generated a liquid-phase protective layer at the interface and alleviated the detrimental effect of free water molecules in deforming the electrode structure. This fundamental understanding sheds light on the mechanistics of the improved cell 
cyclability with $0.5 \mathrm{~m} \mathrm{Li}_{2} \mathrm{SO}_{4}$, providing $0.20 \%$ capacity-fading rate per cycle for 200 cycles in half-cells and $0.06 \%$ fading rate per cycle with $3 \mathrm{~m} \mathrm{Li}_{2} \mathrm{SO}_{4}$ for 500 cycles in full-cells. The insight into the interfacial structure paves the way for the design of stable, inexpensive, and safe aqueous LIBs by tailoring the anion species and interfacial environments.

\section{Declarations}

\section{SUPPLEMENTARY INFORMATION}

Method, electrochemical and chemical analyses, details of computational data.

\section{NOTES}

The authors declare no competing financial interest.

\section{ACKNOWLEDGMENT}

This work was supported by the KAIST Global Singularity Research Program for 2021 and the National Research Foundation of Korea (NRF) grant funded by the Korea government (MSIT) (no. NRF2017R1A5A1015365). Soft XAS experiments were performed under the approval of the program committee (No. S17024, S18003, and S18030) of Ritsumeikan University.

\section{References}

1. Alias, N. \& Mohamad, A. A. Advances of aqueous rechargeable lithium-ion battery: A review. J. Power Sources 274, 237-251, (2015).

2. Wang, Y. G., Yi, J. \& Xia, Y. Y. Recent Progress in Aqueous Lithium-lon Batteries. Adv. Energy Mater. 2, 830-840, (2012).

3. Eftekhari, A. High-Energy Aqueous Lithium Batteries. Adv. Energy Mater. 8, 1801156, (2018).

4. Ramanujapuram, A. et al. Degradation and stabilization of lithium cobalt oxide in aqueous electrolytes. Energy Environ. Sci. 9, 1841-1848, (2016).

5. Gordon, D. et al. Enhancing cycle stability of lithium iron phosphate in aqueous electrolytes by increasing electrolyte molarity. 6, 1501805, (2016).

6. Byeon, P. et al. Atomic-scale observation of $\mathrm{LiFePO}_{4}$ and $\mathrm{LiCoO}_{2}$ dissolution behavior in aqueous solutions. Adv. Funct. Mater. 28, 1804564, (2018).

7. Oh, H., Yamagishi, H., Ohta, T. \& Byon, H. R. Understanding the interfacial reactions of $\mathrm{LiCoO}_{2}$ positive electrodes in aqueous lithium-ion batteries. Mater. Chem. Front. 5, 3657-3663, (2021). 
8. Suo, L. M. et al. "Water-in-salt" electrolyte enables high-voltage aqueous lithium-ion chemistries. Science 350, 938-943, (2015).

9. Suo, L. M. et al. Advanced High-Voltage Aqueous Lithium-Ion Battery Enabled by "Water-in-Bisalt" Electrolyte. Angew. Chem. Int. Ed. 55, 7136-7141, (2016).

10. Yamada, Y. et al. Hydrate-melt electrolytes for high-energy-density aqueous batteries. Nat. Energy 1 , 16129, (2016).

11. McEldrew, M., Goodwin, Z. A. H., Kornyshev, A. A. \& Bazant, M. Z. Theory of the double layer in waterin-salt electrolytes. J. Phys. Chem. Lett. 9, 5840-5846, (2018).

12. Vatamanu, J. \& Borodin, O. Ramifications of Water-in-Salt Interfacial Structure at Charged Electrodes for Electrolyte Electrochemical Stability. J. Phys. Chem. Lett. 8, 4362-4367, (2017).

13. Suo, L. M. et al. How Solid-Electrolyte Interphase Forms in Aqueous Electrolytes. J. Am. Chem. Soc. 139, 18670-18680, (2017).

14. Wang, J. H. et al. Fire-extinguishing organic electrolytes for safe batteries. Nat. Energy 3, 22-29, (2018).

15. Reber, D., Kuhnel, R. S. \& Battaglia, C. Suppressing crystallization of water-in-salt electrolytes by asymmetric anions enables low-temperature operation of high-voltage aqueous batteries. ACS Mater. Lett. 1, 44-51, (2019).

16. Motzko, M., Solano, M. A. C., Jaegermann, W. \& Hausbrand, R. Photoemission Study on the Interaction Between $\mathrm{LiCoO}_{2}$ Thin Films and Adsorbed Water. J. Phys. Chem. C119, 23407-23412, (2015).

17. Shu, Q., Chen, L., Xia, Y. Y., Gong, X. G. \& Gu, X. Proton-Induced Dysfunction Mechanism of Cathodes in an Aqueous Lithium lon Battery. J. Phys. Chem. C 117, 6929-6932, (2013).

18. Gu, X. et al. First-principles study of $\mathrm{H}^{+}$intercalation in layer-structured $\mathrm{LiCoO}_{2}$. J. Phys. Chem. C 115, 12672-12676, (2011).

19. Wang, Y. G., Lou, J. Y., Wu, W., Wang, C. X. \& Xia, Y. Y. Hybrid aqueous energy storage cells using activated carbon and lithium-ion intercalated compounds - III. Capacity fading mechanism of $\mathrm{LiCo}_{1 / 3} \mathrm{Ni}_{1 / 3} \mathrm{Mn}_{1 / 3} \mathrm{O}_{2}$ at different pH electrolyte solutions. J. Electrochem. Soc. 154, A228-A234, (2007).

20. Wang, Y. G., Luo, J. Y., Wang, C. X. \& Xia, Y. Y. Hybrid aqueous energy storage cells using activated carbon and lithium-ion intercalated compounds II. Comparison of $\mathrm{LiMn}_{2} \mathrm{O}_{4}$, $\mathrm{LiCo}_{1 / 3} \mathrm{Ni}_{1 / 3} \mathrm{Mn}_{1 / 3} \mathrm{O}_{2}$, and $\mathrm{LiCoO}_{2}$ positive electrodes. J. Electrochem. Soc. 153, A1425-A1431, (2006).

21. Cherkashinin, G. \& Jaegermann, W. Dissociative adsorption of $\mathrm{H}_{2} \mathrm{O}$ on $\mathrm{LiCoO}_{2}(0 \mathrm{O})$ surfaces: Co reduction induced by electron transfer from intrinsic defects. J. Chem. Phys. 144, 184706, (2016).

22. Tron, A., Jo, Y. N., Oh, S. H., Park, Y. D. \& Mun, J. Surface Modification of the $\mathrm{LiFePO}_{4}$ Cathode for the Aqueous Rechargeable Lithium Ion Battery. ACS Appl. Mater. Interfaces 9, 12391-12399, (2017).

23. Zhi, J., Yazdi, A. Z., Valappil, G., Haime, J. \& Chen, P. Artificial solid electrolyte interphase for aqueous lithium energy storage systems. Sci. Adv. 3, e1701010, (2017). 
24. Lee, H. J. et al. Off-Stoichiometry Induced Few-Nanometer Surface Layer for High-Performance Layered Cathode in Nonaqueous and Aqueous Electrolytes. ACS Appl. Energy. Mater. 1, 5726-5734, (2018).

25. Mizokawa, T. et al. Role of oxygen holes in $\mathrm{Li}_{x} \mathrm{CoO}_{2}$ revealed by soft x-ray spectroscopy. Phys. Rev. Lett. 111, 056404, (2013).

26. Chen, C. H. et al. Soft X-ray absorption spectroscopy studies on the chemically delithiated commercial $\mathrm{LiCoO}_{2}$ cathode material. J. Power Sources 174, 938-943, (2007).

27. Yoon, W. S. et al. Oxygen contribution on $\mathrm{Li}$-ion intercalation-deinterealation in $\mathrm{LiCoO}_{2}$ investigated by O K-edge and Co L-edge X-ray absorption spectroscopy. J. Phys. Chem. B 106, 2526-2532, (2002).

28. Liu, L. J. et al. Electrochemical and in situ synchrotron XRD studies on $\mathrm{Al}_{2} \mathrm{O}_{3}$-coated $\mathrm{LiCoO}_{2}$ cathode material. J. Electrochem. Soc. 151, A1344-A1351, (2004).

29. Bredar, A. R. C., Chown, A. L., Burton, A. R. \& Farnum, B. H. Electrochemical Impedance Spectroscopy of Metal Oxide Electrodes for Energy Applications. ACS Appl. Energy. Mater. 3, 66-98, (2020).

30. Menetrier, M., Saadoune, I., Levasseur, S. \& Delmas, C. The insulator-metal transition upon lithium deintercalation from $\mathrm{LiCoO}_{2}$ : electronic properties and 7Li NMR study. J. Mater. Chem. 9, 1135-1140, (1999).

31. Nakayama, M., Ikuta, H., Uchimoto, Y. \& Wakihara, M. Study on the AC impedance spectroscopy for the $\mathrm{Li}$ insertion reaction of $\mathrm{Li}_{\mathrm{x}} \mathrm{La}_{1 / 3} \mathrm{NbO}_{3}$ at the electrode-electrolyte interface. J. Phys. Chem. B 107, 10603-10607, (2003).

32. Lee, S. W. et al. The Nature of Lithium Battery Materials under Oxygen Evolution Reaction Conditions. J. Am. Chem. Soc. 134, 16959-16962, (2012).

33. Schulz, N., Hausbrand, R., Wittich, C., Dimesso, L. \& Jaegermann, W. XPS-Surface Analysis of SEI Layers on Li-Ion Cathodes: Part II. SEI-Composition and Formation inside Composite Electrodes. J. Electrochem. Soc. 165, A833-A846, (2018).

34. Zhang, J. N. et al. Dynamic evolution of cathode electrolyte interphase (CEI) on high voltage LiCoO2 cathode and its interaction with Li anode. Energy Storage Mater. 14, 1-7, (2018).

35. Zhang, Y. J. \& Cremer, P. S. Interactions between macromolecules and ions: the Hofmeister series. Curr. Opin. Chem. Biol. 10, 658-663, (2006).

36. Reber, D., Grissa, R., Becker, M., Kuhnel, R. S. \& Battaglia, C. Anion Selection Criteria for Water-in-Salt Electrolytes. Adv. Energy Mater. 11, 2002913, (2021).

37. Lim, J. et al. Nanometric Water Channels in Water-in-Salt Lithium lon Battery Electrolyte. J. Am. Chem. Soc. 140, 15661-15667, (2018).

38. Su, H. L., Lan, M. T., Lin, K. W. \& Hsieh, Y. Z. J. E. Chaotropic salts: Novel modifiers for the capillary electrophoretic analysis of benzodiazepines. Electrophoresis 29, 3384-3390, (2008).

39. Schwierz, N., Horinek, D., Sivan, U. \& Netz, R. R. Reversed Hofmeister series-The rule rather than the exception. Curr. Opin. Colloid Interface Sci. 23, 10-18, (2016). 
40. Omta, A. W., Kropman, M. F., Woutersen, S. \& Bakker, H. J. Negligible effect of ions on the hydrogenbond structure in liquid water. Science 301, 347-349, (2003).

41. Kitadai, N. et al. Effects of ions on the $\mathrm{OH}$ stretching band of water as revealed by ATR-IR spectroscopy. J. Solut. Chem. 43, 1055-1077, (2014).

42. Liu, J. H., Zhang, Y. H., Wang, L. Y. \& Wei, Z. F. Drawing out the structural information of the first layer of hydrated ions: ATR-FTIR spectroscopic studies on aqueous $\mathrm{NH}_{4} \mathrm{NO}_{3}, \mathrm{NaNO}_{3}$, and $\mathrm{Mg}\left(\mathrm{NO}_{3}\right)_{2}$ solutions. Spectroc. Acta Pt. A-Molec. Biomolec. Spectr. 61, 893-899, (2005).

43. Cheng, F. Q. et al. FTIR analysis of water structure and its influence on the flotation of arcanite $\left(\mathrm{K}_{2} \mathrm{SO}_{4}\right)$ and epsomite $\left(\mathrm{MgSO}_{4} \cdot 7 \mathrm{H}_{2} \mathrm{O}\right)$. Int. J. Miner. Process. 122, 36-42, (2013).

44. Wei, Z. F., Zhang, Y. H., Zhao, L. J., Liu, J. H. \& Li, X. H. Observation of the first hydration layer of isolated cations and anions through the FTIR-ATR difference spectra. J. Phys. Chem. A 109, 13371342, (2005).

45. Chen, Y., Zhang, Y. H. \& Zhao, L. J. ATR-FTIR spectroscopic studies on aqueous $\mathrm{LiClO}_{4}, \mathrm{NaClO}_{4}$, and $\mathrm{Mg}\left(\mathrm{ClO}_{4}\right)_{2}$ solutions. Phys. Chem. Chem. Phys. 6, 537-542, (2004).

46. Dubouis, N. et al. The role of the hydrogen evolution reaction in the solid-electrolyte interphase formation mechanism for "Water-in-Salt" electrolytes. Energy Environ. Sci. 11, 3491-3499, (2018).

47. Lee, M. H. et al. Toward a low-cost high-voltage sodium aqueous rechargeable battery. Mater. Today 29, 26-36, (2019).

48. Cammarata, L., Kazarian, S. G., Salter, P. A. \& Welton, T. Molecular states of water in room temperature ionic liquids. Phys. Chem. Chem. Phys. 3, 5192-5200, (2001).

49. O'Brien, J. T., Prell, J. S., Bush, M. F. \& Williams, E. R. Sulfate Ion Patterns Water at Long Distance. J. Am. Chem. Soc. 132, 8248-8249, (2010).

50. Kasuya, M. et al. Anion Adsorption on Gold Electrodes Studied by Electrochemical Surface Forces Measurement. J. Phys. Chem. C 120, 15986-15992, (2016).

51. Sverjensky, D. A. \& Fukushi, K. Anion adsorption on oxide surfaces: Inclusion of the water dipole in modeling the electrostatics of ligand exchange. Environ. Sci. Technol. 40, 263-271, (2006).

52. Bhattacharjee, S. \& Khan, S. The wetting behavior of aqueous imidazolium based ionic liquids: a molecular dynamics study. Phys. Chem. Chem. Phys. 22, 8595-8605, (2020).

53. Gorska, B., Timperman, L., Anouti, M. \& Beguin, F. Effect of low water content in protic ionic liquid on ions electrosorption in porous carbon: application to electrochemical capacitors. Phys. Chem. Chem. Phys. 19, 11173-11186, (2017).

54. Chiang, C. H., Chen, C. C., Nazeeruddin, M. K. \& Wu, C. G. A newly developed lithium cobalt oxide super hydrophilic film for large area, thermally stable and highly efficient inverted perovskite solar cells. J. Mater. Chem. A 6, 13751-13760, (2018).

55. Lim, H. K., Lee, H. \& Kim, H. A Seamless Grid-Based Interface for Mean-Field QM/MM Coupled with Efficient Solvation Free Energy Calculations. J. Chem. Theory Comput. 12, 5088-5099, (2016). 
56. Zheng, J. X. et al. Understanding Thermodynamic and Kinetic Contributions in Expanding the Stability Window of Aqueous Electrolytes. Chem 4, 2872-2882, (2018).

57. Rull, F. \& Ohtaki, H. Raman spectral studies on ionic interaction in aqueous alkali sulfate solutions. Spectroc. Acta Pt. A-Molec. Biomolec. Spectr. 53, 643-653, (1997).

58. Rull, F. Raman-spectroscopic study of the ion association of lithium-sulfate aqueous-solutions. $Z$. Naturfors. Sect. A-J. Phys. Sci. 50, 292-300, (1995).

59. Hoshino, S. et al. Reversible three-electron redox reaction of $\mathrm{Mo}^{3+} / \mathrm{Mo}^{6+}$ for rechargeable lithium batteries. ACS Energy Lett. 2, 733-738, (2017).

60. Nitta, K., Sakai, S., Fukunaga, A., Okuno, K. \& Yabuuchi, N. (US Patent App. 16/494,080, 2020).

\section{Figures}


(a)

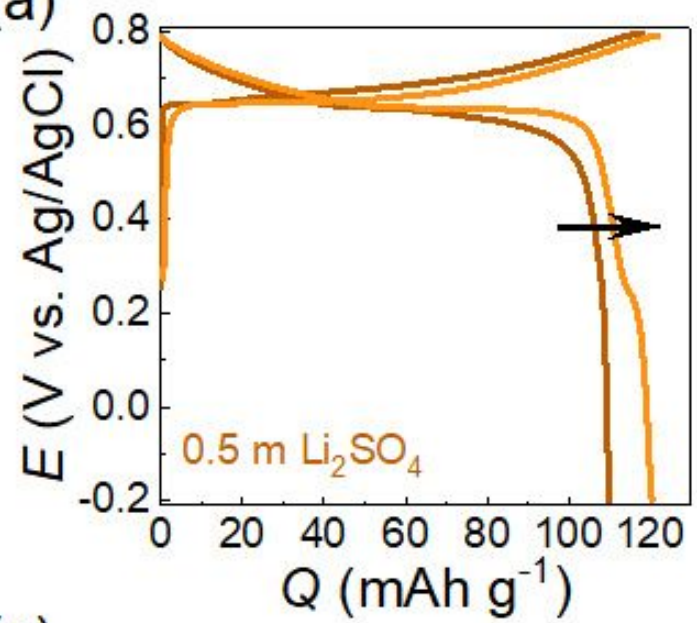

(c)

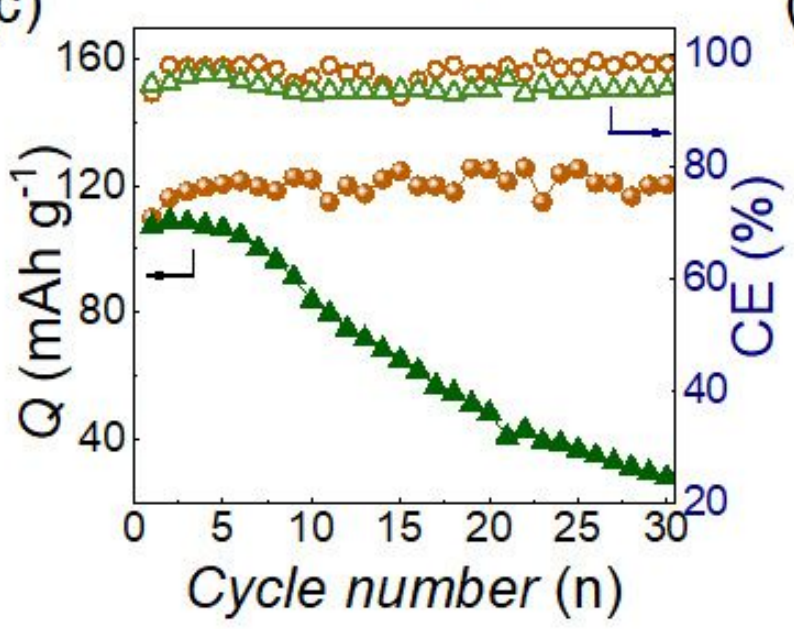

(e)

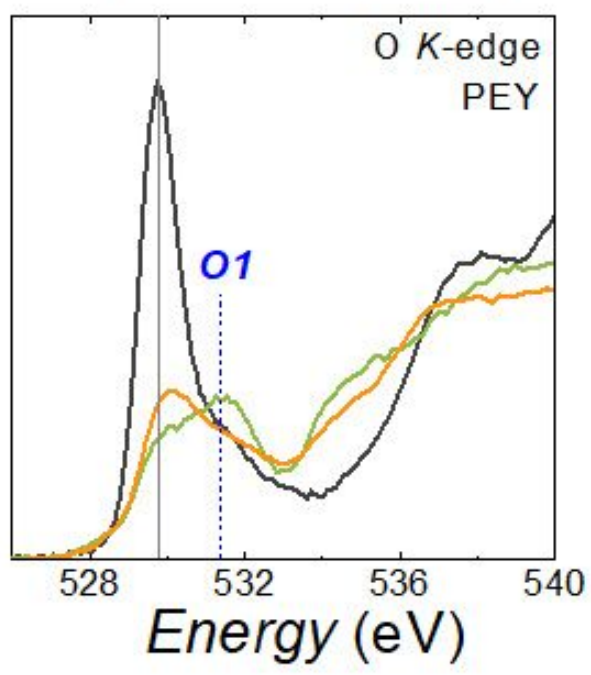

(b)

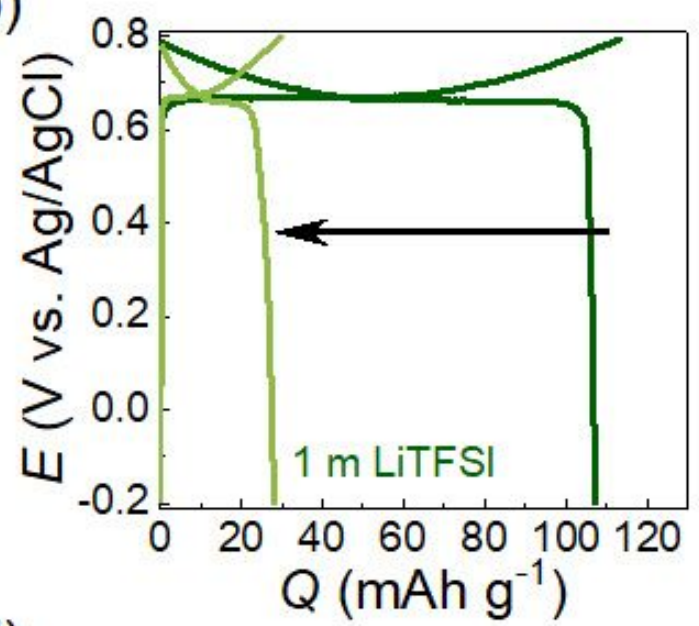

(d)

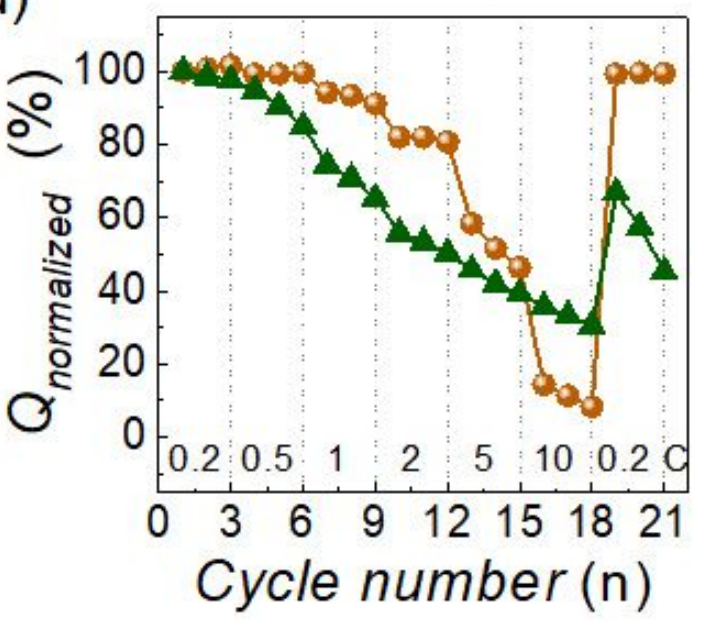

(f)

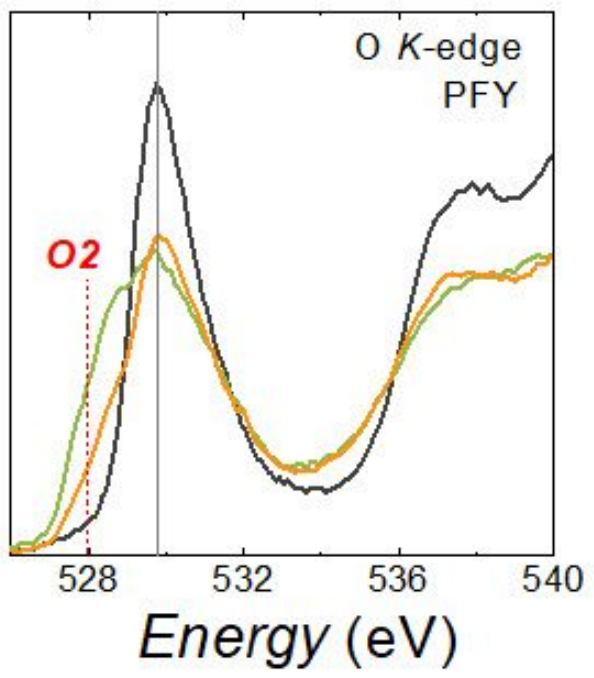

Figure 1

Galvanostatic examinations and X-ray analyses of LCO electrodes with $0.5 \mathrm{~m} \mathrm{Li} 2 \mathrm{SO} 4$ (orange) and $1 \mathrm{~m}$ LiTFSI (green). (a-c) Potential profiles of (a) $0.5 \mathrm{~m}$ Li2SO4 and (b) $1 \mathrm{~m} \mathrm{LiTFSI} \mathrm{for} \mathrm{1st} \mathrm{(dark)} \mathrm{and} \mathrm{30th}$ cycle (light) at $0.5 \mathrm{C}$, and (c) comparison of capacity retention ( $Q$ ) and Coulombic efficiency (CE). (d) Rate capability from $0.2 \mathrm{C}$ to $10 \mathrm{C}$. (e-f) XAFS analyses of 30th cycled LCO electrodes with $0.5 \mathrm{~m} \mathrm{Li} 2 \mathrm{SO} 4$ (orange) and $1 \mathrm{~m}$ LiTFSI (green) and pristine LCO (black) in (e) O K-edge PEY and (f) O K-edge PFY 

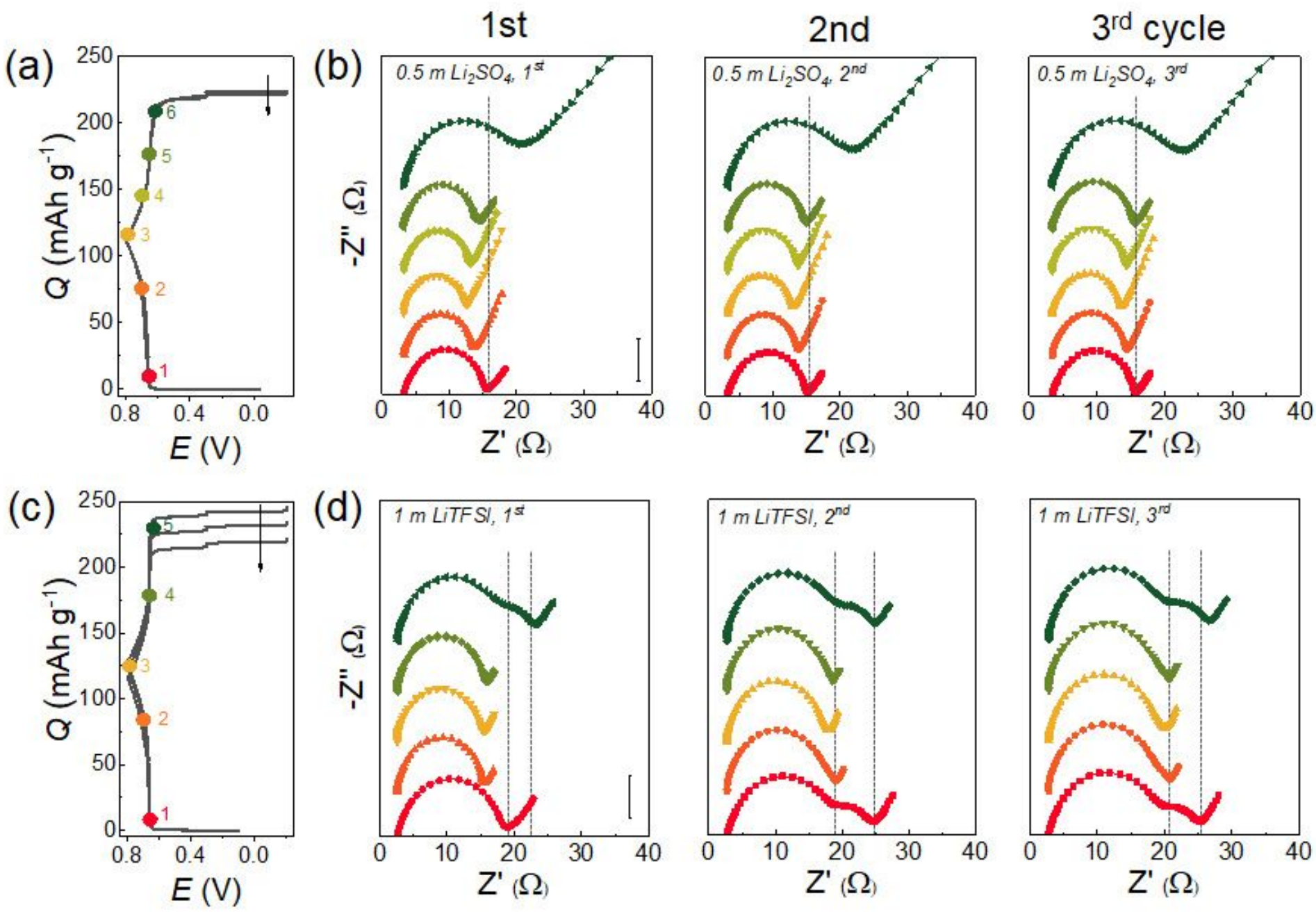

Figure 2

Galvanostatic profiles and corresponding EIS analysis of LCO cells with (a-b) $0.5 \mathrm{~m} \mathrm{Li2SO} 4$ and (c-d) $1 \mathrm{~m}$ LiTFSI for consecutive 3 cycles. Nyquist plots in (b) and (d) were acquired after holding for $10 \mathrm{~min}$ at the point 1 (red, $0.66 \mathrm{~V}$ ), 2, (orange, $0.7 \mathrm{~V}$ ), and 3 (yellow, $0.8 \mathrm{~V}$ ), and subsequent discharge, 4 (light green, 0.7 V), 5 (green, $0.66 \mathrm{~V}$ ), and 6 (dark green, $0.63 \mathrm{~V}$, Li2SO4 only) in the galvanostatic tests in (a) and (c), respectively. The arrows in (a) and (c) indicate from the 1 st to the 3rd cycle. The panels in (b) and (d) correspond the 1st (left), 2nd (middle), and the 3rd cycle (right). The y-axis scales indicate $5 \Omega$. 
(a)

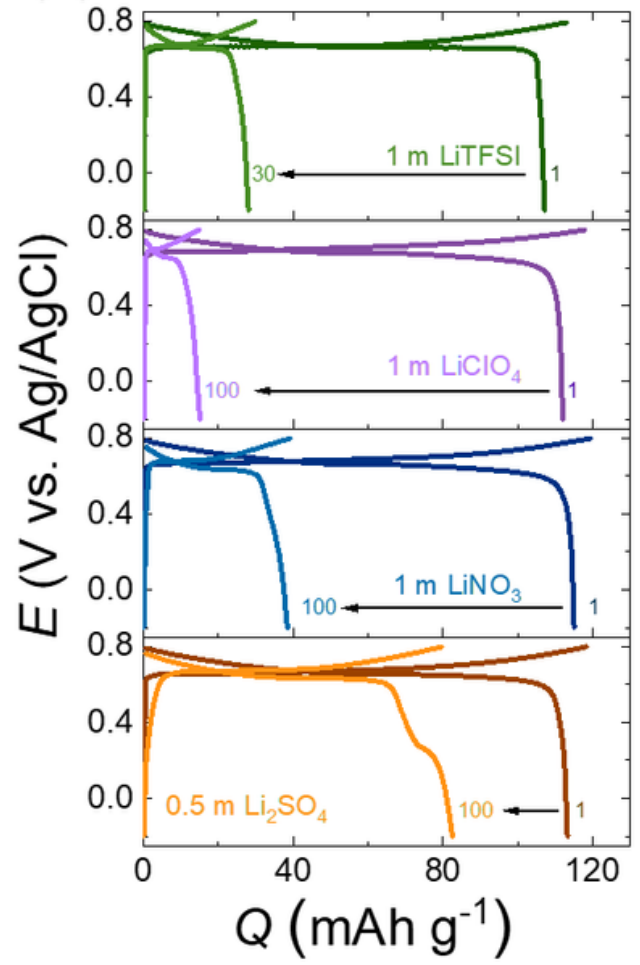

(b)

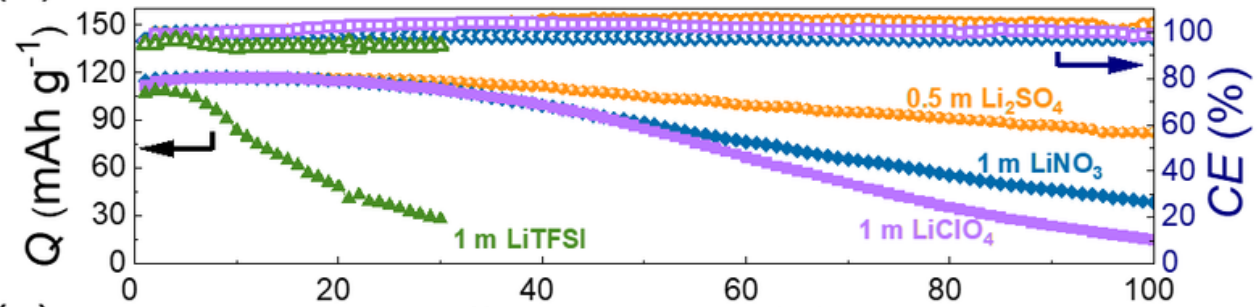

(c)

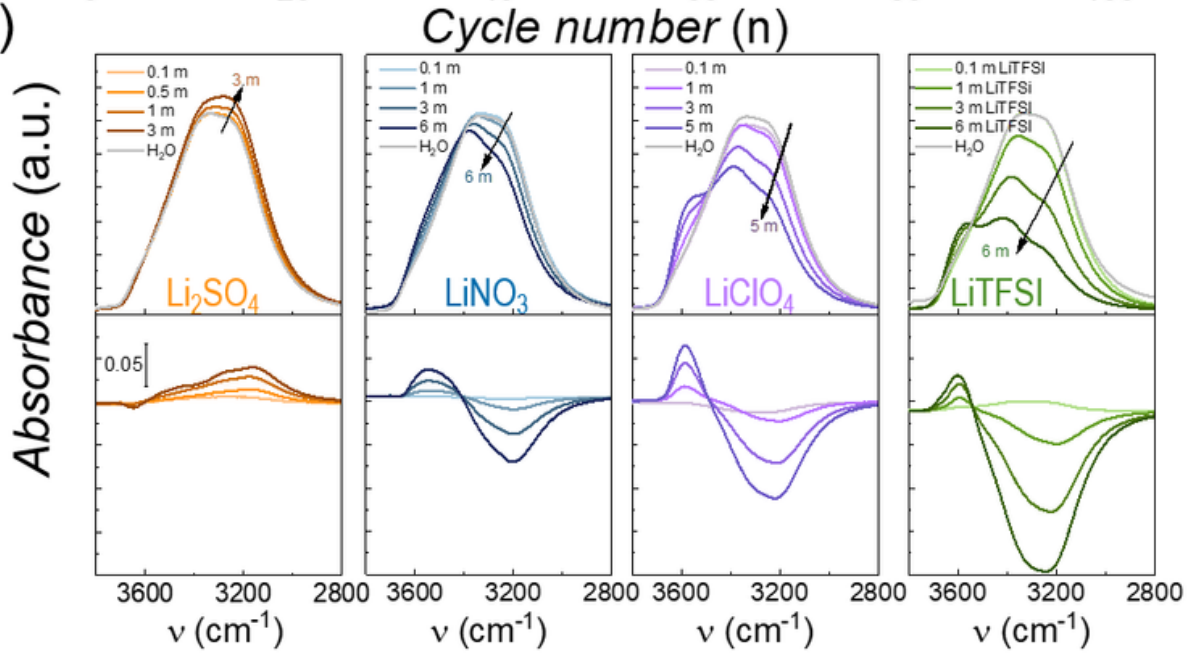

\section{Figure 3}

Galvanostatic cycling and ATR-IR analysis with various electrolytes, Li2SO4 (orange), LiNO3 (blue), LiClO4 (purple), and LiTFSI (green). (a) Potential profiles of LCO at 1st and 100th cycles with $0.5 \mathrm{~m}$ Li2SO4, $1 \mathrm{~m}$ LiNO3, $1 \mathrm{~m} \mathrm{LiClO4}$, and $1 \mathrm{~m} \mathrm{LiTFSI} \mathrm{(from} \mathrm{bottom} \mathrm{to} \mathrm{top).} \mathrm{The} \mathrm{potential} \mathrm{range} \mathrm{was}-0.2 \sim 0.8$ $\mathrm{V}$ vs. $\mathrm{Ag} / \mathrm{AgCl}$ and the current rate was $0.5 \mathrm{C}$. (b) Corresponding capacity retention and $\mathrm{CE}$ for 100 cycles. (c) ATR-IR spectra of OH stretching bands (top) and differential signals from pure water (bottom) with increasing electrolyte concentrations. 

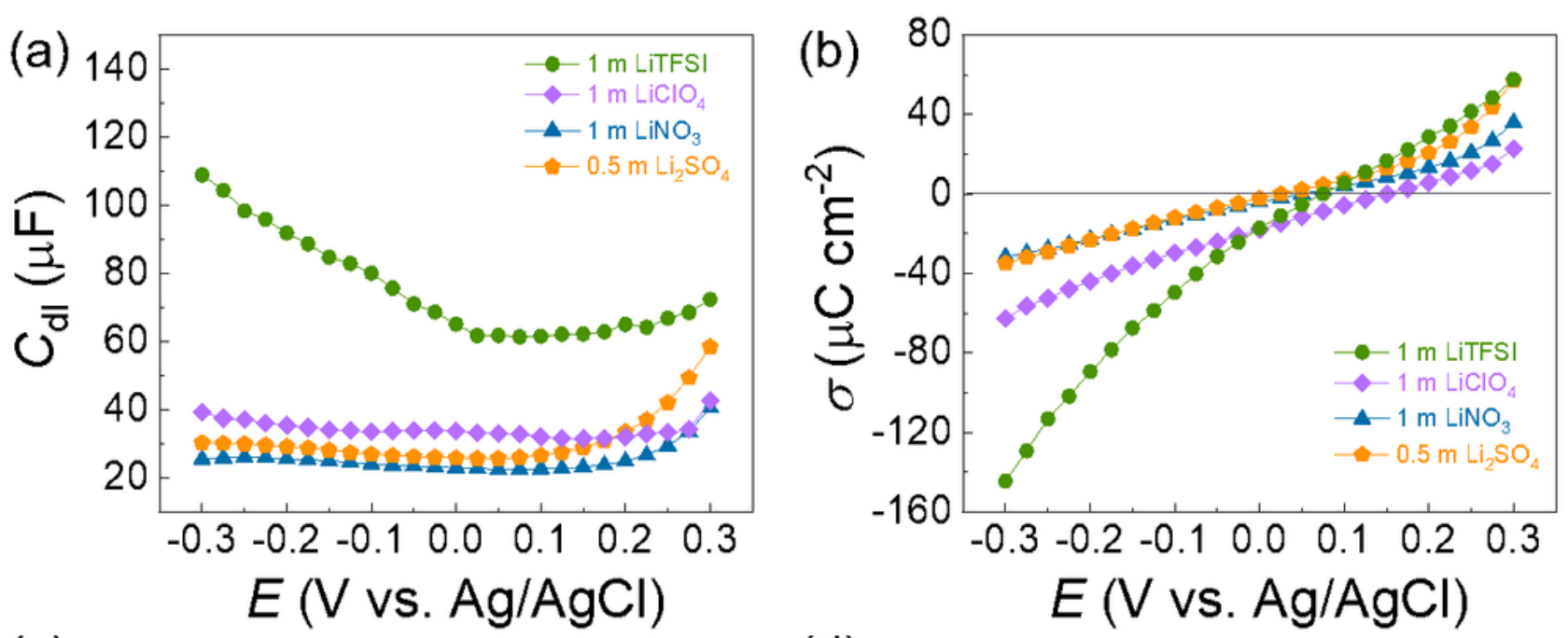

(c)

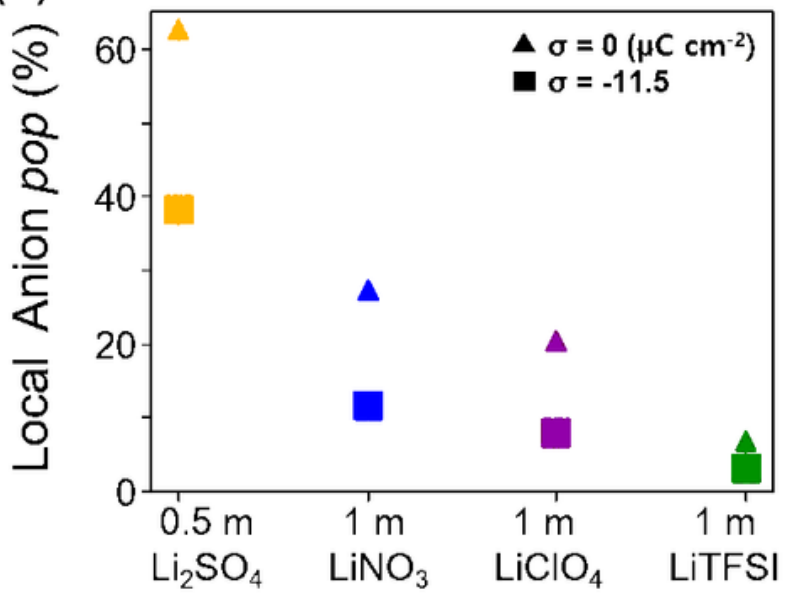

(e)

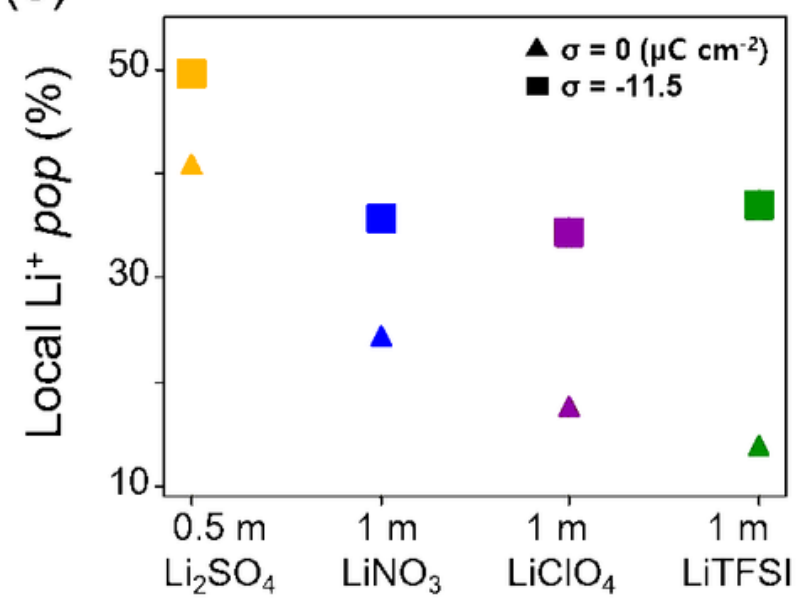

(f)
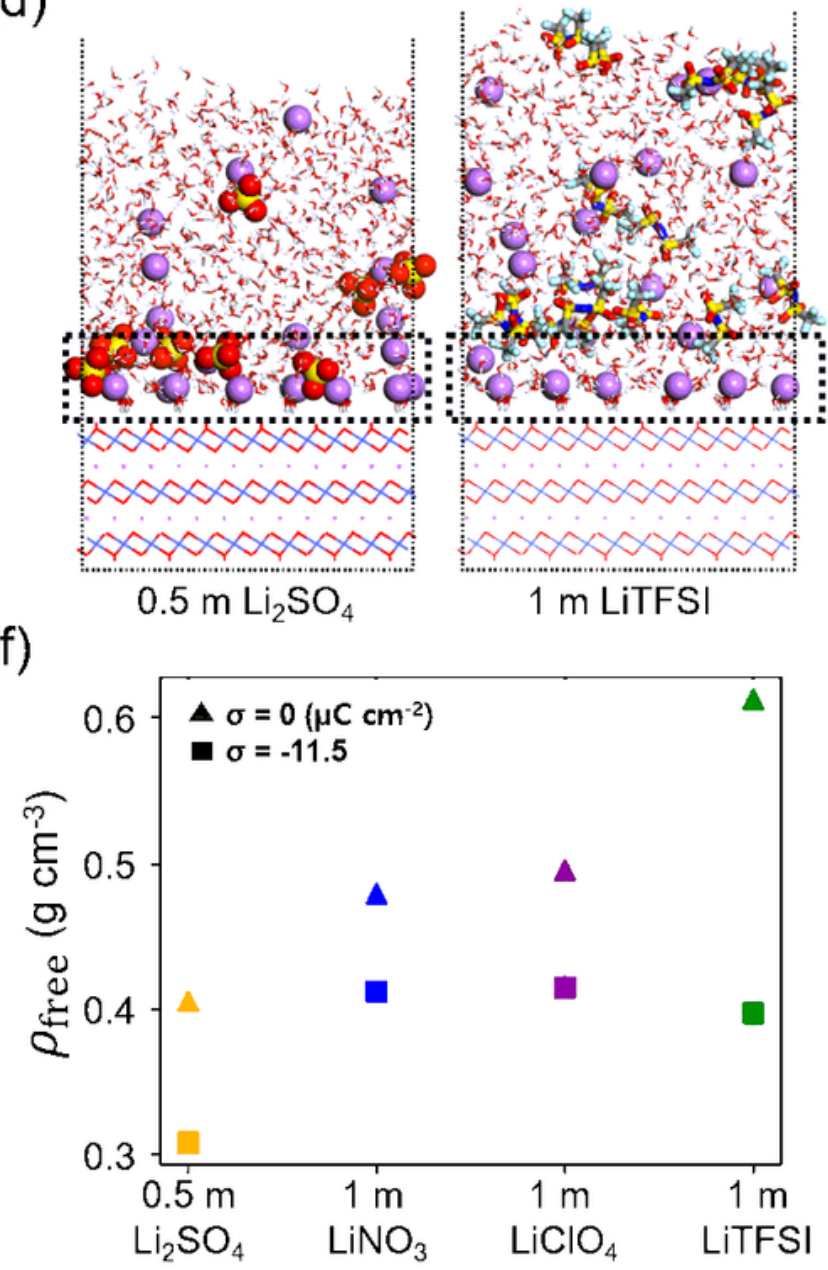

Figure 4

Comparative estimations of the concentration of ions. (a) Electric double-layer capacitance (Cdl) measured by stair-case EIS and (b) corresponding surface charge density $(\sigma)$. Mean-field QM/MM simulation results showing (c) a local anion population (pop), (d) representative structural details when

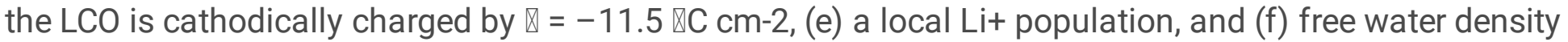
( $\rho_{-}$free) in the interfacial region. Color codes for (d) are; purple for $\mathrm{Li}+$, red for $\mathrm{O}$, yellow for $\mathrm{S}$, grey for $\mathrm{C}$, 
and cyan for F. Li+ and SO42- are displayed using spheres while water and LCO are displayed using sticks.
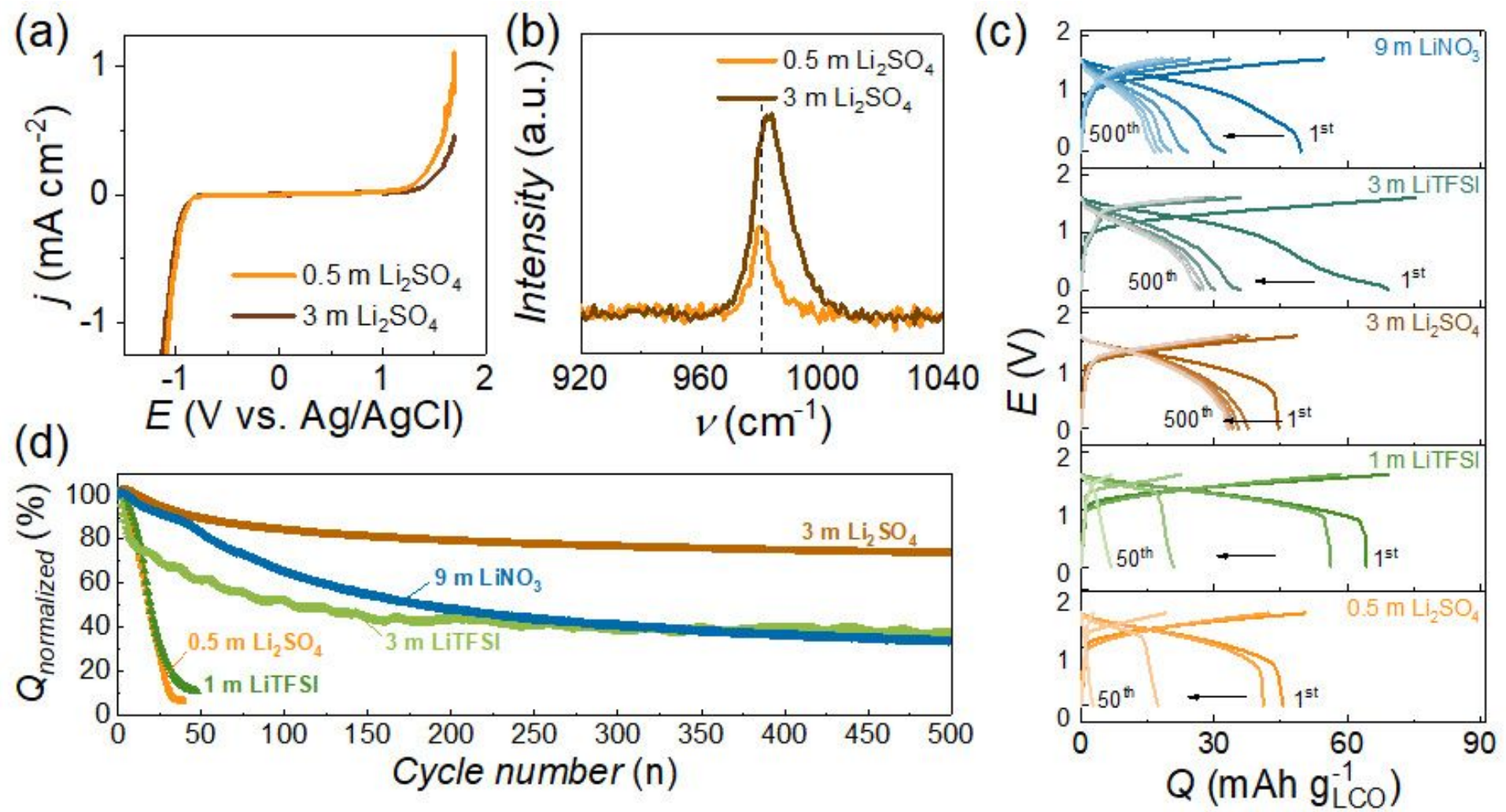

Figure 5

Characterization of high concentration of electrolytes and galvanostatic cycling performance of full cells. (a) Electrochemical potential windows for $0.5 \mathrm{~m}$ (orange) and $3 \mathrm{~m}$ (brown) Li2SO4 at a scan rate of 0.2 $\mathrm{mV} \mathrm{s}$-1. (b) Raman spectra of S042- stretching mode with different concentrations. (c) Voltage profiles of full cells with $0.5 \mathrm{~m}$ Li2SO4, $1 \mathrm{~m}$ LiTFSI for 50 cycles, and $3 \mathrm{~m}$ Li2SO4, $3 \mathrm{~m} \mathrm{LiTFSI}$, and $9 \mathrm{~m}$ LiNO3 for 500 cycles (bottom to top). The negative electrode was Li9/7-xNb2/7Mo3/702 (LNMO) and the current rate was $0.5 \mathrm{C}$. (d) Corresponding capacity retention for total 500 cycles.

\section{Supplementary Files}

This is a list of supplementary files associated with this preprint. Click to download.

- OhandShinetalSIsubmission.docx 